\title{
Diabetes and Hypertension
}

\author{
Nabil K Elnaggar*
}

President of Jeddah Diabetes Club \& Hypertension \& Atherosclerosis Club, P.O Box 10153, Jeddah 21433, KSA

*Corresponding author: Nabil Kamal Elnaggar, Head of Diabetes Center, Hai Aljamea Hospital, Internal Medicine, P.O Box 10153, 21433, Jeddah, Jeddah 21433, Saudi Arabia, Tel: 00966505353650; Mobile: +966505353650; Fax: 00966126803380; E-mail: nelnaggar@yahoo.com

Received date: Dec 10, 2014, Accepted date: Dec 24, 2014, Published date: Dec 30, 2014

Copyright: (C) 2014 Elnaggar NK, This is an open-access article distributed under the terms of the Creative Commons Attribution License, which permits unrestricted use, distribution, and reproduction in any medium, provided the original author and source are credited.

\begin{abstract}
The prevalence of hypertension is increasing worldwide, with an estimated 972 million adults with hypertension in 2000 that is predicted to grow to 1.56 billion by 2025, while diabetes worldwide prevalence is estimated as 382 million in 2012 projected to reach 592 billion in 2030. Diabetes mellitus and hypertension are interrelated diseases that strongly expose patients to increased risk of atherosclerotic cardiovascular and kidney disease. The prevalence of coexisting hypertension and diabetes appears to be increasing in industrialized nations because populations are aging and both hypertension and T2DM (type2 diabetes mellitus) incidence increases with age. A number of possible reasons have been adduced for this coexistence and it is postulated that both diseases share common pathogenetic factors such as insulin resistance, aging, obesity, chronic subclinical inflammatory processes beside the use of thiazide diuretics in subjects initially with hypertension and the development of nephropathy in those initially with diabetes, especially type 1 . Diabetes may also be associated with systolic hypertension secondary to atherosclerosis. In addition both conditions show familiar clustering, which makes it likely to be polygenic in origin. In Diabetics, increased plasma viscosity, stiffness of large arteries, increased production of oxidative radicals and excessive AGEs formation (Advanced Glycation End products) are relevant factors for the development of hypertension. Data from clinical trials emphasize the need for vigilant blood pressure control in patients with diabetes and hypertension. A target blood pressure goal $<140 / 90 \mathrm{mmHg}$ is recommended by some guidelines while others still recommend more tight control of $<130 / 80$. Evidence shows that, to achieve the set goal, use of multipledrug antihypertensive therapy is required. Agents should be used that have been shown to reduce cardiovascular risk, while not worsening concomitant conditions. It is appropriate that an agent that can block RAAS, such as an ACE inhibitor or an ARB should be the first choice in monotherapy and should be one of the partner drugs used in combination in hypertensive patients with diabetes or glucose intolerance.
\end{abstract}

Keywords: Hypertension; Diabetes; Cardiovascular diseases; Apolipoprotein; Glucose tolerance

\section{Introduction}

The prevalence of hypertension is increasing worldwide, with an estimated 972 million adults with hypertension in 2000 that is predicted to grow to 1.56 billion by 2025 ; while diabetes worldwide prevalence is estimated as 382 million in 2012 projected to reach 592 billion in 2030 .

Diabetes mellitus and hypertension are interrelated diseases that strongly expose patients to highly increased risk of atherosclerotic cardiovascular and kidney disease. This association has been called the deadly duet in order to emphasise the increased cardiovascular risk when the two conditions co-exist. Hypertension affects approximately $70 \%$ of patients with diabetes and is approximately twice as common in persons with diabetes as in those without. The prevalence of coexisting hypertension and diabetes appears to be increasing in industrialized nations because populations are aging and both hypertension and T2DM (Type 2 Diabetes Mellitus) incidence increases with age, beside the effect of current improvement in health care.

Hypertensive people are 2.5 times more likely to develop diabetes mellitus within five years [1]. In the Hong Kong Cardiovascular Risk Factor Prevalence Study, only $42 \%$ of people with diabetes had normal blood pressure and only $56 \%$ of people with hypertension had normal glucose tolerance [2]. In US population, hypertension occurs in approximately $30 \%$ of patients with type 1 diabetes and in $50 \%$ to $80 \%$ of patients with type 2 diabetes [3].

Hypertensive disease has been implicated in $4.4 \%$ of deaths coded to diabetes, and diabetes was involved in $10 \%$ of deaths coded to hypertensive disease. Indeed, an estimated $35 \%$ to $75 \%$ of diabetic cardiovascular and renal complications can be attributed to hypertension. The presence of hypertension causes a 7.2-fold increase and a 37-fold increase in mortality in diabetic patients and in diabetic nephropathy respectively.

Diabetes mellitus is an independent risk factor for coronary artery disease, and the risk is markedly increased when hypertension is present. Hypertension also contributes to diabetic retinopathy, which is the leading cause of newly diagnosed blindness, Also the cerebrovascular arterial bed had been demonstrated to be largely affected by the duet; as it was found an increase in intima-media thickness in diabetics of $0.005 \mathrm{~mm}$ with every additional year of age, carotid damage occurred in $23 \%$ of the diabetics, $12 \%$ of the hypertensive patients and $3.4 \%$ of the controls [4].

There are particular subpopulations in which the coexistence of hypertension and diabetes can pose serious risks. Pregnant women with diabetes and hypertension are at risk for pre-eclampsia. Children with type 1 diabetes and hypertension are particularly vulnerable to 
early end-organ disease. The increase in incidence of childhood type 2 diabetes is worrisome, as cardiovascular risk factors early in life can cause accelerated atherosclerosis in early life.

For all these data both hypertension and diabetes should be diagnosed early and treated aggressively to prevent associated microvascular and macrovascular morbidity and mortality.

\section{The Pathophysiology}

A number of possible reasons have been adduced for this coexistence; it was postulated that both diseases share common pathogenetic factors such as insulin resistance, aging, obesity, chronic subclinical inflammatory processes and use of thiazide diuretics in subjects initially with hypertension and the development of nephropathy in those initially with diabetes, especially type 1 . Diabetes may also be associated with systolic hypertension secondary to atherosclerosis.

In addition the two disorders show familiar clustering, which makes it likely to be polygenic in origin. Genetic variants in the gene encoding angiotensinogen, adrenomedullin, apolipoprotein, and $\alpha$ adducin have been reported to be associated with common conditions such as diabetes, hypertension, dysglycemia, or metabolic syndrome [5-8].

The insulin resistance hypothesis is gaining more acceptance as a common aetiological factor for both diseases [9]; "the common soil hypothesis" is a term coined to point out that the two diseases originate from the same soil rooting from insulin resistance [10]. Insulin resistance is associated with impaired insulin signalling, impaired fibrinolysis, and inflammation. A high insulin level was assumed to cause hypertension through its role in the development of increased arterial stiffness, and increased vascular volume by salt and water retention, and finally, by stimulating the sympathetic nervous system, which causes a state of persistent vasoconstriction, ultimately leading to hypertension $[11,12]$. Insulin resistance arises due to various genetic, acquired, and environmental factors leading to visceral obesity. Increased rennin-angiotensin-aldosterone system (RAAS) activity may also cause insulin resistance via the stimulation of Ang II type 1 receptors, which trigger increased production of reactive oxygen species (ROS) in adipocytes, skeletal muscle, and cardiovascular tissue of obese individuals [13-15].

It has been demonstrated in multiple studies that plasma insulin response to a glucose challenge in a glucose tolerance test was twice as high in individuals with hypertension and obesity as in the control subjects, indicating that these individuals were clearly insulin resistant. Systolic blood pressure was directly correlated to the two hours plasma insulin level. There was a linear relationship between serum insulin level and the magnitude of blood pressure elevation [16,17].

Another important factor is the elevation of plasma viscosity which is a feature of diabetic blood, resulting in greater flow resistance and a high incidence of circulatory complications related to the corresponding increase in fibrinogen level [18-21].

An increasing bulk of evidence suggests that free radical over generation may be considered the key in the development of insulin resistance, diabetes and cardiovascular disease [22]. It has been demonstrated that insulin resistance in humans is associated with reduced intracellular antioxidant defence [23], and that diabetic subjects prone to complications may have a defective intracellular antioxidant response [24,25], configuring what is called genetic predisposition to diabetes, as well as liability to its late complications, which might be based on this deficient ROS-scavenging ability in Bcells and/or in target tissues such as endothelium.

The role of the stiff large arteries in diabetics and their contribution to hypertension development have been largely emphasized. Both the hypertensive and the diabetic patients have an increased stiffness of their large arteries. Even in the early stage of hypertension, there is evidence for reduced large artery compliance [26]. Changes of arterial stiffness in diabetes have been reviewed by Stehouwer and Ferreira [27]. Recent studies investigating the association between both type 1 and type 2 diabetes and arterial stiffness have consistently shown that these patients have stiffer arteries than non-diabetic subjects. In both groups of patients, arterial stiffness precedes clinical cardiovascular disease. In type 1 diabetes, increased pulse pressure, a common marker of arterial stiffness was detected in patients in their early thirties. In type 2 diabetes, macrovascular changes also begin at the prediabetic stage [27]. These data support the concept that diabetes, in part, has a vascular etiology.

Several mechanisms have been implicated in the diabetes-associated increase in arterial stiffness. Tropeano AI, et al. [28] showed that glycemia was the major determinant of arterial stiffness in diabetic patients. Hyperglycemia causes endothelial dysfunction which in turn causes arterial stiffness [29,30]. An alternative or additional mechanism of large artery stiffness in diabetes is the AGE-related stiffening of collagen in the vessel wall through provoking endothelial dysfunction. Evidence for such a mechanism has been derived from studies with drugs that interfere with the formation of these glycosylated vessel wall molecules [31]. Also, it was found that in both diabetes and hypertension there was extensive remodelling and narrowing of small vessels that was attributed to inward eutrophic remodelling without net cell growth induced by chronic vasoconstriction [32-34]. In diabetic patients, a clear increase in the media cross-sectional area in small vessels has been observed, suggesting the presence of hypertrophic remodelling. This hypertrophy may be related to a cellular growth response to increased levels of insulin or insulin-like growth factor $1[35,36]$.

\section{Management}

As previously emphasized, diabetics and hypertensive patients should be identified early and treated promptly to achieve the target goals of control of both conditions. Critical evidence from several large scale studies indicated that tight control of diabetes and hypertension can effectively and robustly decrease the risk of the associated high mortality and morbidity or even delay the complication development. It has been estimated that blood pressure reduction of $2 \mathrm{mmHg}$ decreases the risk of cardiovascular events by $7-10 \%$ [37]. Drug therapy is required in the management of these patients, but lifestyle modification and weight management are key components to reduce glycemia and control blood pressure.

The UK Prospective Diabetes Study (UKPDS) showed that blood pressure control helps to prevent cardiovascular complications in patients with type 2 diabetes: each $10 \mathrm{mmHg}$ decrease in mean systolic blood pressure was associated with $12 \%$ reduction in the risk for any complication related to diabetes, $15 \%$ reduction in deaths related to diabetes, $11 \%$ reduction in myocardial infarction and $13 \%$ reduction in microvascular complications and there was no threshold of blood pressure where risk was not observed. In the same study, it has been 
Page 3 of 6

shown that tight control of BP was even more protective than glucose tight control as long as macrovascular events were concerned [38].

The HOPE study [39] (The Heart Outcomes Prevention Evaluation study) showed that inhibition of angiotensin-converting enzyme in patients with type 2 diabetes significantly reduces the risk of vascular complications.

Despite the availability of numerous effective antihypertensive medications, many diabetic-hypertensive adults remain uncontrolled for various reasons, including inadequate treatment or noncompliance. Among hypertensive patients receiving treatment, the estimated proportion of patients with blood pressure uncontrolled to $<140 / 90 \mathrm{~mm} \mathrm{Hg}$ ranges from $47 \%$ to $84 \%$ in Europe and North America.

Furthermore, a subset of patients who adhere, continue to be uncontrolled, The HOT (Hypertension Optimal Treatment study) [40] showed that diabetics will need 2-3 drugs to control their BP.

The Systolic Hypertension in the Elderly Program (SHEP) [41] and other studies like HDFP [42], Syst-Euro [43], HOT [40], normotensive ABCD [44], and HOPE [39] provide firm evidence that even small BP reductions translate to significant decrease in both micro and macrovascular complications in persons with type 2 diabetes. The ADVANCE study [45] Showed that intensive control of BP resulted in reduction in composite micro and macrovascular complications by $9 \%$, coronary events by $14 \%$ and renal events by $21 \%$.

In diabetics, a target blood pressure goal of $<130 / 80$ was previously recommended by most of the guideline-developing authorities especially in the case of nephropathic diabetics which is a very common early complication among them; a new recommended target of $<140 / 90 \mathrm{mmHg}$ which is both reasonable and safe to achieve has been recommended by a number of recent guidelines including the 2013 European Society of Hypertension/European Society of Cardiology, and the JNC 8 guidelines. The 2013 American Diabetes Association guidelines recommend a target of $<140 /<80$ and $<130 /<80$ in some diabetic populations such as younger patients if it can be achieved without undue treatment burden, moreover, the 2014 American Society of Hypertension/International Society of Hypertension guidelines recommends the old target of $<130 / 80$ for diabetics as stated "lower targets than 140/90 may be appropriate in some populations such as African Americans, the elderly, the LV hypertrophy patients, those with systolic/diastolic dysfunction, diabetes mellitus or those with chronic kidney disease". However, the Canadian hypertension 2013 guidelines, and NICE (National Institutes of Clinical excellence) 2014 guidelines still recommends a target of $<130 / 80$ especially if diabetes is present with nephropathy.

In fact, although a number of studies (UKPDS and Hypertension Optimal Treatment (HOT), and normotensive ABCD trial) have demonstrated the improved outcomes in patients assigned to lower blood pressure targets, which goes in harmony with the results of The Advance Collaborative Group study demonstrating the benefit of an angiotensin-converting enzyme (ACE) inhibitor and indapamide in a fixed combination, and strongly suggesting that the blood pressure goal $(<130 / 80 \mathrm{mmHg})$ was beneficial; The ACCORD trial was unable to find a significant reduction in incidence of major $\mathrm{CV}$ events in patients with diabetes whose SBP was lowered to an average of $119 \mathrm{mmHg}$ compared with patients whose SBP remained at an average of $133 \mathrm{mmHg}$. Other trials of rigorous control like ACTIVE, INVEST (DM) [46], ONTARGET [47], NAVIGATOR [48], TRANSCEND
[49], AND RAODMAP [50], demonstrated no extra benefit in high risk patients.

A conflicting situation arises when comparing previous epidemiological analyses showing that blood pressure $\geq 120 / 70 \mathrm{mmHg}$ is associated with increased cardiovascular event rates and mortality in patients with diabetes and the recent data of outcome results of intervention to achieve blood pressure $<120 / 70$ demonstrating increased risk of CV risk. These results had revived the "J-Curve" concept relating the effect of tight reduction below 120/70 on coronary flow leading to increased CHD risk. The approach and type of medications used in the intervention may have a role in the increased risk found in these studies.

Based on recent outcome studies, the ESC/ESH guidelines 2013 [51], state that "Whether the presence of microvascular disease (renal, ocular, or neural) in diabetes requires treatment initiation and targets of lower BP values is also unclear. Although, micro albuminuria can be delayed or reduced by hypertension treatment; trials in diabetic populations, including normotensives and hypertensive, have been unable to demonstrate consistently that proteinuria reduction is also accompanied by a reduction in hard CV outcomes".

It became crystal clear that in order to achieve the set goal of $<140 / 90 \mathrm{mmHg}$, use of multiple-drug antihypertensive therapy is required. Agents should be used on an evidence base proof for their ability to reduce the cardiovascular risk, while not worsening concomitant conditions, e.g. new onset diabetes or abnormal lipids or even precipitate new disease. The European Society of Hypertension guidelines in 2013 [51] stated that "A meta-analysis of more than 40 studies has shown that combining two agents from any two classes of antihypertensive drugs increases the $\mathrm{BP}$ reduction much more than increasing the dose of one agent. The advantage of initiating with combination therapy is a prompter response in a larger number of patients (potentially beneficial in high-risk patients), a greater probability of achieving the target BP in patients with higher BP values, and a lower probability of discouraging patient adherence with many treatment changes. Indeed, a recent survey has shown that patients receiving combination therapy have a lower drop-out rate than patients given any monotherapy. A further advantage is that there are physiological and pharmacological synergies between different classes of agents that may not only justify a greater BP reduction but also cause fewer side-effects and may provide larger benefits than those offered by a single agent."

Because of a greater effect of RAAS (Renin-AngiotensinAldosterone System) blockers on urinary protein excretion, it appears reasonable to have either an ACE (Angiotensin converting enzyme) inhibitor or an ARB (angiotensin receptor blockers) in the combination based on their proven efficacy and safety trials. Clinical trials with diuretics, beta blockers, ACE inhibitors, ARBs and calciumchannel antagonists have all demonstrated benefit in the treatment of hypertension in type I diabetes mellitus, as well as type 2 diabetes mellitus. This benefit is related to the degree of blood-pressure lowering. A sub-analysis of the ACCOMPLISH [52] trial has reported that the association of an ACE inhibitor with a calcium antagonist, rather than a thiazide diuretic, is more effective in preventing doubling serum creatinine and ESRD, though less effective in preventing proteinuria. 
Page 4 of 6

\section{Effects of Drugs on Both Diseases}

\section{Effects of anti-hypertensives on diabetes}

All the major classes of antihypertensive can be used in diabetics, but the thiazide diuretics and beta-blockers have metabolic side-effects such as increasing insulin resistance or direct diabetogenesis, which make them less appropriate as first line agents [53]. RAAS blockers and calcium channel antagonists are suitable as first line antihypertensive in diabetics. The calcium channel blockers (CCBs) and RAAS blockers have better metabolic profiles and the latter reduce insulin resistance and may improve glycemia in diabetics and patients with the metabolic syndrome. RAAS blockers may also have a renal protective effect in incipient nephropathy [54].

The use of CCBs was not significantly associated with incident diabetes compared to other antihypertensive agents: the association with diabetes was lowest for ACEIs and ARBs, followed by CCBs, $\beta$ blockers, and diuretics [55]. Further, it was surprisingly discovered recently that calcium channel blockers can even prevent diabetes and increase B cell survival. The mechanisms behind that is thought to be through the inhibition of the expression of a protein called TXNIP (Thioredoxin Interacting Protein) in human islets and that orally administered verapamil resulted in reduction of TXNIP expression and B-cell apoptosis, enhanced endogenous insulin levels, and rescued mice from STZ-induced diabetes. Verapamil also promoted B-cell survival and improved glucose homeostasis and insulin sensitivity in $\mathrm{ob} / \mathrm{ob}$ mice [56].

\section{Effects of anti-diabetics on blood pressure}

Table 1 shows the currently approved anti-diabetic agents, their cellular mechanisms and physiologic actions. The mechanisms mentioned involve their antidiabetic actions which can be related to side actions where changes of blood pressure subsequently occurs, such as the case of insulin and SGLT-2 inhibitors; insulin causes salt and water retention, increases body weight and it causes growth of tissues as an anabolic hormone, on the contrary leading to elevations in blood pressure, on the contrary, SGLT-2 inhibitors causes osmotic diuresis leading to blood pressure reduction [57-60]. Other medications, such as GLP-1 agonists and DPP-4 inhibitors have been demonstrated to exert their effects directly through the activation of their receptors on the cardiac and vascular tissues or centrally positioned receptors. Table 2 demonstrates the effects of the different anti-diabetics on blood pressure [61-63]

\begin{tabular}{|c|c|c|c|c|c|c|}
\hline \multicolumn{7}{|c|}{ Oral Antidiabetic Agents } \\
\hline Class & Biguanides & $\begin{array}{l}\text { Sulphonylurea } \\
\text { Glinides }\end{array}$ & Dpp-4 Inhibitors & TZDS & $\begin{array}{l}\text { Alpha Glucosidase } \\
\text { Inhibitors }\end{array}$ & Sglt2 Inhibitors \\
\hline Name & Metformin & $\begin{array}{l}\text { Glibenclamide } \\
\text { Glimepride } \\
\text { Gliclazide } \\
\text { Repaglinide }\end{array}$ & $\begin{array}{l}\text { Sitagliptin } \\
\text { Vildagliptin } \\
\text { Saxagliptin } \\
\text { Linagliptin }\end{array}$ & Pioglitazone & $\begin{array}{l}\text { Acarbose } \\
\text { Miglitol }\end{array}$ & $\begin{array}{l}\text { Canagliflozin } \\
\text { Empagliflozin } \\
\text { Dapagliflozin }\end{array}$ \\
\hline Cellular Mechanism & $\begin{array}{l}\text { activates } \\
\text { kinase }\end{array}$ & $\begin{array}{l}\text { closes } k+\text { channels on } \\
b \text { cell }\end{array}$ & $\begin{array}{l}\text { Inhibits glp-1 } \\
\text { degrading enzyme }\end{array}$ & $\begin{array}{l}\text { activates } \\
\text { nuclear ppar } \\
\text { receptors }\end{array}$ & $\begin{array}{l}\text { inhibits intestinal } \\
\text { alpha glucosidase }\end{array}$ & $\begin{array}{l}\text { inhibits sod/glucose } \\
\text { transporter } 2\end{array}$ \\
\hline Main Actions & $\begin{array}{l}\text { decrease hepatic } \\
\text { glucose output }\end{array}$ & increases insulin secretion & $\begin{array}{l}\text { increases insulin } \\
\text { decreases glucagon }\end{array}$ & $\begin{array}{l}\text { increase } \\
\text { insulin } \\
\text { sensitivity }\end{array}$ & $\begin{array}{l}\text { slow } \\
\text { absorption }\end{array}$ & $\begin{array}{l}\text { inhibits glucose renal } \\
\text { reabsorption }\end{array}$ \\
\hline \multicolumn{7}{|c|}{ Injectable Antidiabetic Agents } \\
\hline Class & \multicolumn{2}{|l|}{ Insulin } & \multicolumn{2}{|l|}{ Glp-i Agonists } & \multicolumn{2}{|l|}{ Amylin Mimetics } \\
\hline Name & \multicolumn{2}{|l|}{$\begin{array}{l}\text { various premixed } \\
\text { short/long acting }\end{array}$} & \multicolumn{2}{|l|}{$\begin{array}{l}\text { Exenatide } \\
\text { Liraglutide } \\
\text { Lixisentaide } \\
\text { Dulaglutide }\end{array}$} & \multicolumn{2}{|l|}{ Pramlintide } \\
\hline Cellular Mechanism & \multicolumn{2}{|c|}{ activates insulin receptors } & \multicolumn{2}{|c|}{ Activates GLP-1 receptors } & \multicolumn{2}{|c|}{$\begin{array}{l}\text { mimics the naturally secreted amylin which is } \\
\text { deficient in diabetics }\end{array}$} \\
\hline Main Actions & \multicolumn{2}{|c|}{$\begin{array}{l}\text { increase glucose disposal } \\
\text { decrease hepatic glucose production }\end{array}$} & \multicolumn{2}{|c|}{$\begin{array}{l}\text { increase insulin secretion } \\
\text { decrease glucagon secretion } \\
\text { increases satiety } \\
\text { slows gastric emptying }\end{array}$} & \multicolumn{2}{|c|}{$\begin{array}{l}\text { slow gastric emptying } \\
\text { regulate postprandial glucagon } \\
\text { increase satiety }\end{array}$} \\
\hline
\end{tabular}

Table 1: The available anti-diabetic agents, their cellular mechanisms and main actions action 
Page 5 of 6

\begin{tabular}{|l|l|}
\hline Effects of Antidiabetic Drugs on Blood Pressure & Effect on Blood Pressure \\
\hline Drug Class & Small increases \\
\hline Insulins & No effect \\
\hline Biguanides (metformin) & No effect \\
\hline Sulphonylureas and Glinides & Small reductions \\
\hline DPP-4 inhibitors & Reduce blood pressure \\
\hline GLP-1 agonists & Reduce blood pressure \\
\hline SGLT-2 inhibitors & No effect \\
\hline Amylin mimetics & \\
\hline
\end{tabular}

Table 2: The effect of the different anti-diabetic drugs on blood pressure

In summary, only insulin can raise blood pressure while other agents are either neutral or of limited power for reduction of blood pressure.

\section{References}

1. Lago RM, Singh PP, Nesto RW (2007) Diabetes and hypertension. Nat Clin Pract Endocrinol Metab 3: 667.

2. Cheung BM (2010) The hypertension-diabetes continuum. J Cardiovasc Pharmacol 55: 333-339.

3. Landsberg L, Molitch M (2004) Diabetes and hypertension: pathogenesis, prevention and treatment. Clin Exp Hypertens 26: 621-628.

4. Gómez-Marcos MA, Recio-Rodríguez JI, Rodríguez-Sánchez E, PatinoAlonso MC, Magallón-Botaya R, et al. (2011) [Carotid intima-media thickness in diabetics and hypertensive patients]. Rev Esp Cardiol 64: 622-625.

5. Ong KL, Tso AW, Leung RY, Cherny SS, Sham PC, et al. (2011) A genetic variant in the gene encoding adrenomedullin predicts the development of dysglycemia over 6.4 years in Chinese. Clin Chim Acta 412: 353-357.

6. Ong KL, Jiang CQ, Liu B, Jin YL, Tso AW, et al. (2011) Association of a genetic variant in the apolipoprotein A5 gene with the metabolic syndrome in Chinese. Clin Endocrinol (Oxf) 74: 206-213.

7. Cheung CY, Tso AW, Cheung BM, Xu A, Ong KL, et al. (2011) Genetic variants associated with persistent central obesity and the metabolic syndrome in a 12-year longitudinal study. Eur J Endocrinol 164: 381-388.

8. Ong KL, Li M, Tso AW, Xu A, Cherny SS, et al. (2010) Association of genetic variants in the adiponectin gene with adiponectin level and hypertension in Hong Kong Chinese. Eur J Endocrinol 163: 251-257.

9. Reaven GM (2011) Relationships among insulin resistance, type 2 diabetes, essential hypertension, and cardiovascular disease: similarities and differences. J Clin Hypertens (Greenwich) 13: 238-243.

10. Stern MP (1995) Diabetes and cardiovascular disease. The "common soil" hypothesis. Diabetes 44: 369-374.

11. Modan M, Halkin H, Almog S, Lusky A, Eshkol A, et al. (1985) Hyperinsulinemia. A link between hypertension obesity and glucose intolerance. J Clin Invest 75: 809-817.

12. Ferrannini E, Buzzigoli G, Bonadonna R, Giorico MA, Oleggini M, et al. (1987) Insulin resistance in essential hypertension. N Engl J Med 317: 350-357.

13. Stump CS, Clark SE, Sowers JR (2005) Oxidative stress in insulinresistant conditions: cardiovascular implications. Treat Endocrinol 4: 343-351.

14. Leiter LA, Lewanczuk RZ (2005) Of the renin-angiotensin system and reactive oxygen species Type 2 diabetes and angiotensin II inhibition. Am J Hypertens 18: 121-128.
15. Sharma AM, Engeli S (2006) The role of renin-angiotensin system blockade in the management of hypertension associated with the cardiometabolic syndrome. J Cardiometab Syndr 1: 29-35.

16. Manicardi V, Camellini L, Bellodi G, Coscelli C, Ferrannini E (1986) Evidence for an association of high blood pressure and hyperinsulinemia in obese man. J Clin Endocrinol Metab 62: 1302-1304.

17. Shen DC, Shieh SM, Fuh MM, Wu DA, Chen YD, et al. (1988) Resistance to insulin-stimulated-glucose uptake in patients with hypertension. J Clin Endocrinol Metab 66: 580-583.

18. Memeh CU, Reid HL (1988) Plasma and serum viscosity in Nigerian diabetics. Acta Diabetol Lat 25: 101-108.

19. McMillan DE (1988) The microcirculation: changes in diabetes mellitus. Mayo Clin Proc 63: 517-520.

20. McMillan DE (1981) Physical factors important in the development of atherosclerosis in diabetes. Diabetes 30: 97-104.

21. Khan TM, Marwat MA, Rehman H (2005) Comparison of plasma viscosity and fibrinogen concentration in hypertensive and normotensive diabetics. J Ayub Med Coll Abbottabad 17: 45-47.

22. Suvarna Prasad, Ajay Kumar Sinha (2010) Free radical activity in hypertensive type 2 diabetic patients. International Journal of Diabetes Mellitus. 1877-5934.

23. Ceriello A, Morocutti A, Mercuri F, Quagliaro L, Moro M, et al. (2000) Defective intracellular antioxidant enzyme production in type 1 diabetic patients with nephropathy. Diabetes 49: 2170-2177.

24. Hodgkinson AD, Bartlett T, Oates PJ, Millward BA, Demaine AG (2003) The response of antioxidant genes to hyperglycemia is abnormal in patients with type 1 diabetes and diabetic nephropathy. Diabetes 52: 846-851.

25. Bruce CR, Carey AL, Hawley JA, Febbraio MA (2003) Intramuscular heat shock protein 72 and heme oxygenase- 1 mRNA are reduced in patients with type 2 diabetes: evidence that insulin resistance is associated with a disturbed antioxidant defense mechanism. Diabetes 52: 2338-2345.

26. Giannattasio C, Failla M, Piperno A, Grappiolo A, Gamba P, et al. (1999) Early impairment of large artery structure and function in type I diabetes mellitus. Diabetologia 42: 987-994.

27. Stehouwer CDA, Ferreira I (2006) Diabetes, lipids and other cardiovascular risk factors. In: Safar M, O’Rourke M, eds. Handbook of Hypertension. Arterial Stiffness in Hypertension. Edinburgh, Scotland: Elsevier 23: 427-456.

28. Tropeano AI, Boutouyrie P, Katsahian S, Laloux B, Laurent S (2004) Glucose level is a major determinant of carotid intima-media thickness in patients with hypertension and hyperglycemia. J Hypertens 22: 2153-2160.

29. McVeigh GE, Brennan GM, Johnston GD, McDermott BJ, McGrath LT, et al. (1992) Impaired endothelium-dependent and independent 
vasodilation in patients with type 2 (non-insulin-dependent) diabetes mellitus. Diabetologia 35: 771-776.

30. Williams SB, Cusco JA, Roddy MA, Johnstone MT, Creager MA (1996) Impaired nitric oxide-mediated vasodilation in patients with noninsulin-dependent diabetes mellitus. J Am Coll Cardiol 27: 567-574.

31. Safar M, O'Rourke M (2006) Handbook of Hypertension. Arterial Stiffness in Hypertension. Edinburgh, Scotland: Elsevier 23: 1-600

32. Rizzoni D, Agabiti Rosei E (2006) Small artery remodeling in hypertension and diabetes. Curr Hypertens Rep 8: 90-95.

33. Porteri E, Rizzoni D, Mulvany MJ, De Ciuceis C, Sleiman I, et al. (2003) Adrenergic mechanisms and remodeling of subcutaneous small resistance arteries in humans. J Hypertens 21: 2345-2352.

34. Bakker EN, van der Meulen ET, van den Berg BM, Everts V, Spaan JA, et al. (2002) Inward remodeling follows chronic vasoconstriction in isolated resistance arteries. J Vasc Res 39: 12-20.

35. Rizzoni D, Porteri E, Guelfi D, Muiesan ML, Valentini U, et al. (2001) Structural alterations in subcutaneous small arteries of normotensive and hypertensive patients with non-insulin-dependent diabetes mellitus. Circulation 103: 1238-1244.

36. Mathiassen ON, Buus NH, Sihm I, Thybo NK, Mørn B, et al. (2007) Small artery structure is an independent predictor of cardiovascular events in essential hypertension. J Hypertens 25: 1021-1026.

37. Lewington S, Clarke R, Qizilbash N, Peto R, Collins R; Prospective Studies Collaboration (2002) Age-specific relevance of usual blood pressure to vascular mortality: a meta-analysis of individual data for one million adults in 61 prospective studies. Lancet 360: 1903-1913.

38. [No authors listed] (1998) Tight blood pressure control and risk of macrovascular and microvascular complications in type 2 diabetes: UKPDS 38. UK Prospective Diabetes Study Group. BMJ 317: 703-713.

39. Hansson L, Zanchetti A, Carruthers SG, Dahlöf B, Elmfeldt D, et al. (1998) Effects of intensive blood-pressure lowering and low-dose aspirin in patients with hypertension: principal results of the Hypertension Optimal Treatment (HOT) randomised trial. HOT Study Group. Lancet 351: 1755-1762.

40. Sverre E Kjeldsen, Thomas Hedner, Kenneth Jamerson, Stevo Julius, William E Haley, et al. (1998) Hypertension Optimal Treatment (HOT) Study Home Blood Pressure in Treated Hypertensive Subjects. Hypertension 31: 1014-1020

41. Curb JD, Pressel SL, Cutler JA, Savage PJ, Applegate WB, et al. (1996) Effect of diuretic-based antihypertensive treatment on cardiovascular disease risk in older diabetic patients with isolated systolic hypertension. Systolic Hypertension in the Elderly Program Cooperative Research Group. JAMA 276: 1886-1892.

42. [No authors listed] (1985) Mortality findings for stepped-care and referred-care participants in the hypertension detection and follow-up program, stratified by other risk factors. The Hypertension Detection and Follow-up Program Cooperative Research Group. Prev Med 14: 312-335.

43. Tuomilehto J, Rastenyte D, Birkenhäger WH, Thijs L, Antikainen R, et al. (1999) Effects of calcium-channel blockade in older patients with diabetes and systolic hypertension. Systolic Hypertension in Europe Trial Investigators. N Engl J Med 340: 677-684.

44. Schrier RW, Estacio RO, Esler A, Mehler P (2002) Effects of aggressive blood pressure control in normotensive type 2 diabetic patients on albuminuria, retinopathy and strokes. Kidney Int 61: 1086-1097.

45. Patel A, MacMahon S, Chalmers J, Neal B, Woodward M, (2007): Effects of a fixed combination of perindopril and indapamide on macrovascular and microvascular outcomes in patients with type 2 diabetes mellitus (the ADVANCE trial): a randomised controlled trial. Lancet 370: 829-840.
46. Cooper-DeHoff RM, Gong Y, Handberg EM, Bavry AA, Denardo SJ, et al. (2010) Tight blood pressure control and cardiovascular outcomes among hypertensive patients with diabetes and coronary artery disease. JAMA 304: 61-68.

47. Deedwania P (2007) Evolving treatment options for prevention of cardiovascular events in high-risk hypertensive patients. J Clin Hypertens (Greenwich) 9: 883-888.

48. NAVIGATOR Study Group, McMurray JJ, Holman RR, Haffner SM, Bethel MA, et al. (2010) Effect of valsartan on the incidence of diabetes and cardiovascular events. N Engl J Med 362: 1477-1490.

49. The TRANSCEND Study group (2008) Effects of the angiotensinreceptor blocker telmisartan on cardiovascular events in high-risk patients intolerant to angiotensin-converting enzyme inhibitors: a randomised controlled trial. Lancet 9644: 1174-1183.

50. Haller H, Ito S, Izzo JL Jr, Januszewicz A, Katayama S, et al. (2011) Olmesartan for the delay or prevention of microalbuminuria in type 2 diabetes. N Engl J Med 364: 907-917.

51. $2013 \mathrm{ESH} / \mathrm{ESC}$ Guidelines for the management of arterial hypertension (2013) The Task Force for the management of arterial hypertension of the European Society of Hpertension (ESH) and of the European Society of Cardiology (ESC) Journal of Hypertension 31: 1281-1357.

52. Kenneth Jamerson, the ACCOMPLISH Trial Investigators (2008) Benazepril plus Amlodipine or Hydrochlorothiazide for Hypertension in High-Risk Patients N Engl J Med 359: 2417.

53. Taylor EN, Hu FB, Curhan GC (2006) Antihypertensive medications and the risk of incident type 2 diabetes. Diabetes Care 29: 1065-1070.

54. Barnett AH (1994) Diabetes and hypertension. Br Med Bull 50: 397-407.

55. Noto H, Goto A, Tsujimoto T, Noda M (2013) Effect of calcium channel blockers on incidence of diabetes: a meta-analysis. Diabetes Metab Syndr Obes 6: 257-261.

56. Xu G, Chen J, Jing G, Shalev A (2012) Preventing $\hat{I}^{2}$-cell loss and diabetes with calcium channel blockers. Diabetes 61: 848-856.

57. Randeree HA, Omar MA, Motala AA, Seedat MA (1992) Effect of insulin therapy on blood pressure in NIDDM patients with secondary failure. Diabetes Care 15: 1258-1263.

58. Kantola I (2002) Effect of metformin on blood pressure. Clin Drug Invest 22: 347-354.

59. Melander A, Bitzén PO, Sartor G, Scherstén B, Wåhlin-Boll E (1990) Will sulfonylurea treatment of impaired glucose tolerance delay development and complications of NIDDM? Diabetes Care 13 Suppl 3: 53-58.

60. White WB, Cannon CP, Heller SR, Nissen SE, Bergenstal RM, et al. (2013) Alogliptin after acute coronary syndrome in patients with type 2 diabetes. N Engl J Med 369: 1327-1335.

61. Ferdinand KC, White WB, Calhoun DA, Lonn EM, Sager PT, et al. (2014) Effects of the once-weekly glucagon-like peptide-1 receptor agonist dulaglutide on ambulatory blood pressure and heart rate in patients with type 2 diabetes mellitus. Hypertension 64: 731-737.

62. Baker WL, Smyth LR, Riche DM, Bourret EM, Chamberlin KW, et al. (2014) Effects of sodium-glucose co-transporter 2 inhibitors on blood pressure: a systematic review and meta-analysis. J Am Soc Hypertens 8: 262-275.

63. Hoogwerf BJ, Doshi KB, Diab D (2008) Pramlintide, the synthetic analogue of amylin: physiology, pathophysiology, and effects on glycemic control, body weight, and selected biomarkers of vascular risk. Vasc Health Risk Manag 4: 355-362. 